\title{
JANE AUSTEN E A IDENTIDADE NACIONAL NOSTÁLGICA DA INGLATERRA
}

\author{
Maria Clara Pivato Biajoli \\ Doutora em Teoria e História Literária (Unicamp) \\ Pós-doutoranda pela USP - Bolsista FAPESP \\ mariabiajoli@gmail.com
}

\section{RESUMO}

O presente artigo analisa o processo de reconstrução da obra da escritora inglesa Jane Austen (1775-1817) desde o fim do século XIX até o período pós-Segunda Guerra Mundial. Esse processo é, em grande parte, responsável pela imagem, que ainda circula atualmente, de seus romances como retratos pacíficos e campestres de uma Inglaterra préRevolução Industrial que foi perdida na modernidade mas que, ainda assim, constitui a essência da identidade inglesa. Trata-se de uma reconstrução que ocorreu tanto no âmbito acadêmico quanto por meio da veneração de seus fãs, os Janeites, e que resultou na transformação de Austen em um patrimônio a ser preservado. Tal resultado, além de consolidar uma interpretação sobre a autora e sua obra, pode ser observado tanto na criação de um museu em sua última casa, Chawton Cottage, como na grande atração de turistas pelos locais mencionados em seus romances ou utilizados como cenários nas recentes adaptações de suas obras para cinema e televisão.

Palavras-chave: Jane Austen, Austenmania, Identidade Nacional, Nostalgia, Rural.

\section{ABSTRACT}

This essay analyses the reconstruction of the work of the English writer Jane Austen (1775-1817) from the final quarter of the 19th century to the post-Second World War period. It aims at understanding the current image of her novels as a peaceful and rural portrait of a pre-Industrial Revolution England that has been lost with the advent of modernity, but still constitutes the foundation of the English national identity. This reconstruction took place due to the Academia and due to the love of her fans, the Janeites, which, together, bestowed upon Austen the status of a national heritage to be preserved. The result, apart from fixing a single interpretation for her work, can be observed in the transformation of her last dwelling, Chawton Cottage, in a museum, as well in the attraction of many tourists for the places mentioned in her novels or used as location for recent TV and film adaptations.

Keywords: Jane Austen, Austenmania, National Identity, Nostalgia, Rural. 
A decisão do governo britânico de colocar o rosto da escritora Jane Austen (ainda que, pode-se argumentar, em uma versão fictícia) no lugar do cientista Charles Darwin na nova nota de dez libras, em circulação desde 2017, foi uma resposta segura a uma campanha pública que pedia a manutenção de personalidades femininas na moeda inglesa após a substituição de Elizabeth Fry por Winston Churchill na nota de cinco libras ${ }^{1}$. Segura porque Austen detém, hoje, um lugar inabalável tanto no cânone tradicional da literatura inglesa como na construção da identidade cultural e nacional de seu país, algo que, como será demonstrado a seguir, ocorreu através de um longo processo de recuperação e ressignificação de suas obras e dos lugares em que a autora viveu e/ou sobre os quais escreveu.

Durante a segunda metade do século XIX, os romances de Jane Austen (1775-1817) foram comercializados envoltos em um tom sentimental, em muitas edições baratas ou resumidos visando a uma leitura rápida, especialmente na década de 1890 . Ao mesmo tempo, graças ao sucesso da biografia A Memoir of Jane Austen (1871), escrita pelo seu sobrinho James Edward Austen-Leigh, a autora foi redescoberta por grandes homens de letras, os quais se identificavam como Janeites e idolatravam a imagem de Austen propagada por James Edward como uma "querida tia" doméstica, inocente e religiosa.

No final da Primeira Guerra Mundial, porém, Austen foi transformada em símbolo de uma Inglaterra que quase deixou de existir por muito pouco, e precisava, portanto, ser restaurada, como uma relíquia de tempos passados. R. W. Chapman, de Oxford, tomou para si esse projeto e publicou, em 1923, novas edições das obras da escritora, aplicando em seus textos os mesmos rigores acadêmicos utilizados nos estudos clássicos para resgatar os

\footnotetext{
${ }^{1}$ Cf: https://www.telegraph.co.uk/women/womens-life/10199138/Jane-Austen-unveiled-as-face-of-new-10note.html Acesso em: 20 fevereiro 2018.
} 
originais da década de 1810 e eliminar toda confusão criada ao longo do século XIX. A novidade que representava essa abordagem precisa ser destacada. Como afirma Claudia Johnson (2012), uma coisa era intelectuais relaxarem após um longo dia de trabalho lendo Jane Austen - "Edward Fitzgerald wrote that Edward Byles Cowell 'constantly reads Miss Austen at night after his Sanscrit Philology is done': it composes him: like Gruel'" (JOHNSON, 2012, p.116) - outra coisa era conferir a ela a mesma importância da filologia do sânscrito. Isso só foi possível porque, segundo Johnson (2012), além da admiração desses intelectuais ingleses e da elite de uma forma geral, no pós-Primeira Guerra a ideia de "clássicos ingleses" como patrimônio ganhou extrema força e aceitação. Como nos lembra Kathryn Sutherland (2005), até mesmo antes da Primeira Guerra a descoberta da resistência da identidade inglesa estava ligada a uma volta à literatura, mas o que a guerra fez foi dar força a essa descoberta, transformando-a em necessidade. Como uma forma, então, de restauração, os Estudos Ingleses e o estabelecimento de um cânone se tornaram questões urgentes nos anos de 1920 e 1930 (SUTHERLAND, 2005, p.52). A literatura passa a representar, assim, uma necessidade de recuperar uma comunidade perdida - afinal, quem somos nós, os ingleses? - e passa a ser revestida de um sentimento de orgulho nacionalista, de reconstrução de uma identidade absolutamente destruída pela guerra. Como coloca Claudia Johnson (2012, p. 125), em termos de recepção de Austen depois do conflito, as personagens nos romances ingleses criam o que Benedict Anderson chamou de uma "comunidade política imaginária" da nação, promovendo, por sua vez, um sentimento de pertencimento que não é limitado por classes ou pelo tempo.

Mas, afinal, do que se trata essa edição de 1923? Na falta dos manuscritos originais de Austen, Chapman dirigiu-se às primeiras edições dos seus romances, acreditando serem elas 
a versão mais próxima do que a autora desejava. No caso dos romances que tiveram segundas edições durante a vida de Austen revisadas pela autora - Razão e Sensibilidade e Mansfield Park -, a primeira edição foi descartada e a segunda edição passou a ser a definitiva, uma escolha que muitos críticos hoje contestam veementemente por acreditarem que muitas modificações foram feitas pelos editores ou tipógrafos, e não pela própria autora. Uma outra característica muito importante dessas edições é a grande quantidade de notas e apêndices explicativos de Chapman. Essas anotações são responsáveis por estruturar a leitura, definir suas referências "corretas" e transformar, assim, os romances de Austen em um material sério (SUTHERLAND, 2005, p.43). Os apêndices também são curiosos por seus assuntos, que incluíam desde os tipos de carruagens da época a posições de dança e enfeites de cabelo. Essas explicações sobre os detalhes do universo do romance, como as diferenças entre uma carruagem barouche e uma cabriolé, indicam uma crença de que não seria possível entender a obra sem essas informações. É muito curioso como hoje esses mesmos assuntos são abordados em diversos workshops em congressos sobre Jane Austen todo ano. De 1811 a 1923 pouco mais de cem anos se passaram, mas todos acreditavam na necessidade das notas de Chapman. Uma avaliação das edições dizia:

The vocabulary of Jane Austen is superficially so like our own as to deceive the unwary into assuming an identity between things in fact as dissimilar as the Pyramids and the Marble Arch. The words are the same but no longer bear the same meaning. [Chapman's] notes [...] enable us to put ourselves in her place and, in reading, to recreate her work within ourselves [...] [but] we cannot obliterate the interval of time between the dead author and ourselves. (apud SUTHERLAND, 2005, p. 358).

O ponto aqui é a exatidão no significado das palavras, é a eliminação de falhas, é ensinar aos leitores a maneira correta de se ler Austen. Chapman (apud SUTHERLAND, 2005, 
p. 28) disse que "those who have made it their business to reconstitute the texts of English classics know that the history of a text is the gradual accretion of error", logo a sua tarefa é corrigir esses erros e fornecer ao público uma nova e desconhecida Jane Austen. Em uma outra crítica sobre as novas edições, E. M. Forster (apud SUTHERLAND, 2005, p. 34) afirmou que, entre seus méritos, está o impulso de despertar o Janeite, que antes lia com sua mente fechada: "after reading its notes and appendixes, after a single glance at its illustrations, he will never relapse again into the primal stupor".

A seleção de Chapman do que deveria ser anotado e do que poderia ser deixado de lado não representa um desejo de uma explicação objetiva do passado, mas a sua escolha de um passado específico. Como nota Claire Harman (2009, p. 158), essa seleção acabou por remover Austen de seu universo particular, realocando-a em um ponto central daquilo que o período regencial representava, especialmente do modo de vida de sua aristocracia tranquilo e rural. Assim, da mesma forma como tanto se esforçaram os descendentes de Austen antes dele, e apesar de todo o seu rigor acadêmico, Chapman retorna à imagem da querida tia Jane. Ele sabia, obviamente, que, no mesmo período em que Austen escrevia, a Inglaterra lidava com os processos de cercamentos das áreas rurais e com a sua industrialização, e que uma longa guerra contra a França se arrastava. Mas isso não aparece de forma direta nos romances, o que os tornava, para ele, provavelmente a última fotografia antes das mudanças que viriam (SUTHERLAND, 2005, p. 50). O botanista e Janeite Reginald Farrer comentou na época:

All the anguish of her time is non-existent to Jane Austen, when once she has got pen in hand, to make us a new kingdom of refuge from the toils and frets of life. [...] It is not without hope or comfort for us nowadays, to remember that Mansfield Park appeared 
the year before Waterloo, and Emma the year after. (FARRER, apud SUTHERLAND, 2005, p. 48).

Assim, podemos afirmar com tranquilidade que a edição de Chapman não efetua o seu idealizado objetivo inicial, um resgate e preservação da Jane Austen "original", mas sim produz uma Jane Austen específica, a partir, principalmente, de seus comentários editoriais. Para os críticos de hoje, as histórias de Austen podem não abordar Napoleão ou a Revolução Industrial, mas a forma como as relações sociais foram expostas dentro da sala de estar em seus interesses mais básicos, a forma como a moralidade da época falhava repetidamente frente à ganância e egoísmo, por exemplo, torna sua obra incrivelmente política, algo que Reginald Ferrer, quando a lê como um refúgio, não conseguiu perceber. Como conclui Claudia Johnson (2012, p. 23), Chapman acabou fazendo mais do que preservar os textos de Austen, ele preservou um senso de estabilidade e encanto da sua época e disponibilizou-o a si próprio e aos seus contemporâneos para ser retomado quando a modernidade se mostrasse muito dura, como na verdade já era.

Os estudos sobre Jane Austen nas universidades foram consolidados também ao longo dessa década de 1920. A coleção completa de Chapman tornou-se a base para uma análise séria dos seus romances e do gênero do romance de forma geral, e a descoberta posterior da produção de juventude da autora (Juvenilia) parecia indicar aos críticos que havia muito mais naqueles livros do que apenas um simples entretenimento para mulheres. Diversos nomes da área concordam hoje que o estudo de Mary Lascelles de 1939, Jane Austen and Her Art, é um marco para essa nova abordagem pois, segundo Harman (2009, p. 182), as especulações inteligentes de Lascelles sobre como Austen conduzia sua carreira e a sua análise do estilo da autora abriram novos caminhos tanto para a crítica quanto para 
biógrafos, e o resultado é que, após a publicação de seu trabalho, ninguém mais questionava se Austen deveria ser comparada com outros grandes romancistas como Dickens ou James, ao mesmo tempo em que o seu papel no processo de modernização do romance também passou a ser reconhecido de forma mais generalizada.

A partir da década de 1940, portanto, Austen foi colocada em um lugar de destaque na academia, para nunca mais ser removida. Em 1948, o professor de Cambridge F. R. Leavis publicaria seu estudo The Great Tradition, que nada mais é do que uma institucionalização do cânone dos clássicos ingleses, no qual Jane Austen faz parte como a pioneira. Já lan Watt, em seu Rise of the Novel (1957), enxergaria Austen como a herdeira direta de Samuel Richardson, Henry Fielding e Daniel Defoe, a responsável por combinar seus estilos e criar o romance moderno maduro. Esses estudos foram responsáveis por associar definitivamente Austen a um tipo de escrita, a qual, segundo Clara Tuite (2002, p. 5), era dependente de uma construção da imagem da autora como aristocrata, pertencente à elite agrária anterior ao capitalismo e detentora de grandes propriedades, as quais, por sua vez, representavam a Inglaterra e, mais ainda, toda a Grã-Bretanha. Austen é símbolo de uma "vida civilizada" que é, obviamente, a vida das elites. O fato de que a autora passou toda a sua vida adulta com uma renda muito limitada e, após a morte de seu pai, dependendo da ajuda dos irmãos é totalmente esquecido nessa nova mística, que se apropria de sua obra e permanece com força até os dias de hoje, quando filmes baseados em seus romances se esforçam cada vez mais para mostrar mansões luxuosas, joias finas e roupas elaboradas. A entrada de Austen no cânone literário, portanto, foi conquistada através da sua associação com a cultura da elite inglesa. 
Fora da academia, a popularidade de Austen e o amor dos Janeites resistia fortemente, tendo até inspirado um conto de Rudyard Kipling, de 1924, que se passa durante a Primeira Guerra, cujo título é The Janeites. O crédito pela criação do termo Janeite, porém, é tradicionalmente dado a George Saintsbury, crítico inglês que, em seu prefácio para uma edição de Orgulho e Preconceito de 1894, confessou ser um "Jane Austenite". Esse culto a Jane Austen começou com a publicação do Memoir de Austen-Leigh, e seus seguidores se consideravam exclusivos pelo seu entendimento de Austen, quase como uma irmandade formada por aqueles que tinham a capacidade rara de admirá-la. Como coloca Claudia Johnson,

By the end of the nineteenth century, Janeites were a discernible and decidedly (though not exclusively) masculine readership of publishers, professors, novelists, and literati [...]. At the Royal Society of Literature in particular, Austen's novels were celebrated with an enthusiasm that would seem crazy if it were enacted in classrooms or conferences today. These Janeites flaunted their devotion: Austen was their dear Jane, their matchless Jane, and they are her cult, her sect, her little company (fit though few), her tribe of adorers who discuss and re-discuss the miracle of her work in extravagant, patently hyperbolic terms. As Montague Summers [...] put it in a 1917 address to the Royal Society of Literature, 'to-day the world is divided between the elect and the profane - those who admire Jane Austen, and those (one shudders to speak the phrase) - who do not'". (JOHNSON, 2012, p. 8-9).

A superioridade desse grupo se baseava na ideia de que, como afirmou Virginia Woolf (1924, s/p.) muitos anos depois, "of all great writers she [Austen] is the most difficult to catch in the act of greatness". Ou seja, entender a qualidade da obra de Austen não seria para qualquer um. A adoração Janeite também levou às primeiras visitas aos lugares relacionados a Austen e a suas obras, especialmente no interior rural da Inglaterra, e também à publicação do primeiro "guia turístico" sobre a autora, o livro de Constance Hill 
Jane Austen: Her Homes and Her Friends (1902). Os mesmos lugares listados por Hill são ainda hoje grandes pontos de atração dos fãs atuais da autora, mas a lista cresceu e passou a incluir também as grandes mansões utilizadas nas adaptações para o cinema e TV, como as propriedades de Lyme Park e Chatsworth House, que foram escolhidas para representar a famosa Pemberley de Mr. Darcy em 1995 e 2005, respectivamente.

Contudo, é na versão de 1926 do já mencionado conto de Kipling que encontramos uma das primeiras associações de Austen com a Inglaterra como um todo de forma simbólica. Nessa versão, o autor incluiu um último verso ao poema "Jane’s Marriage", que, em 1924, atuava como epígrafe à história. Trata-se de uma ode à Austen e a sua Inglaterra:

Jane lies in Winchester-blessed be her shade!

Praise the Lord for making her, and her for all she made!

And while the stones of Winchester, or Milsom Street, remain,

Glory, love, and honour unto England's Jane

(KIPLING, 1926, s/p.)

Em sua homenagem, Kipling combina elementos da vida da autora (pedras de Winchester, onde passou seus últimos meses e está enterrada) com referências à sua obra (Milsom Street, uma rua na cidade de Bath que aparece em Northanger Abbey e Persuasão). O mais interessante, contudo, é o último verso, no qual o autor associa Jane à Inglaterra, já que sua obra traz glória, amor e honra para o país. Ele mesmo um Janeite, Kipling reforça a ideia de que Austen se transformou em um símbolo e patrimônio inglês e de que, enquanto os lugares associados a ela permanecerem intactos, podemos entender que assim também sobreviverá a Inglaterra. Com a explosão da Segunda Guerra Mundial, isso ficou ainda mais necessário porque agora a pátria estava sendo atacada. Quando a Luftwaffe alemã bombardeou Bath em 1942, qual não teria sido o medo de ver as sagradas pedras de Milsom 
Street destruídas? Se na Primeira Guerra seus romances foram usados como refúgio para escapar dos horrores do conflito, como aparece no conto de Kipling, agora eles eram símbolo da resistência.

Claudia Johnson (2012, p. 128) nos mostra que, durante a Segunda Guerra, de algo reconfortante Austen passou a ser encarada como o núcleo de uma versão da identidade inglesa conectada com a ideia de um lar sob ataque. Mais ainda, as pessoas começaram a se lembrar de que Austen escreveu seus romances durante um longo esforço de guerra da Inglaterra contra Napoleão Bonaparte, e ela se tornou então exemplo de como resistir e suportar o que estava acontecendo. Johnson cita, por exemplo, a escritora e tradutora Laura Ragg, que defendia os paralelos entre o período de Austen e a guerra que começava em 1939. Segundo ela, Austen conhecia a sólida postura demonstrada pelos ingleses em mais de vinte anos de guerra, com suas privações e sofrimentos e, por isso, o que antes parecia uma calmaria imperturbável nos seus romances era, na verdade, essa atitude firme de uma nação que aguentava tudo em um esforço heroico (JOHNSON, 2012, p.129). Ragg compara, por exemplo, a situação da Segunda Guerra com a personagem Elinor Dashwood de Razão e Sensibilidade, que mantém seus sentimentos sob controle - tristeza pela situação financeira precária, desesperança por saber que o homem que ama está noivo de outra - tudo para poder apoiar sua mãe e irmãs. O silêncio de Elinor não significa ausência de emoções, muito pelo contrário. Da mesma forma, o silêncio de Austen sobre a guerra estaria, na verdade, permeado por sua presença (JOHNSON, 2012, p. 129).

É também dentro desse discurso que Hollywood lançaria, em 1940, o primeiro filme baseado em um romance de Austen, Orgulho e Preconceito, com Greer Garson e Laurence Olivier nos papéis principais. Entre outros aspectos que valem a pena ser comentados, 
devemos apontar as semelhanças entre os cenários e as vestimentas do filme $E$ o Vento Levou..., lançado apenas um ano antes, uma forma, talvez, de conectar a Inglaterra com os EUA e apelar para o saudosismo do público norte-americano - alguns críticos acreditavam que se tratava até de uma tentativa de mobilizar a opinião pública para que os EUA entrassem na guerra, o que só ocorre no final de 1941. Além disso, já na abertura somos informados de que a história "happened in Old England..." (PRIDE, 1940, p. 52). Como o filme se distancia muito do romance original para criar uma comédia romântica leve, o efeito é a criação de uma "antiga Inglaterra" tranquila e pacífica, o oposto do cenário de guerra daquele momento, indicando então para seus espectadores não só que a Inglaterra corria perigo, mas que essa Inglaterra específica poderia ser perdida com a guerra. O filme, segundo Johnson (2012, p.128), parece funcionar em duas direções opostas, mas que não se contradizem: por um lado, como entretenimento, ajudava o público a esquecer a guerra, mas, por outro lado, parecia convocá-los para resistir, lembrando-os do que estava em jogo.

É também durante a Segunda Guerra que um grupo de admiradores inicia uma campanha pública de coleta de fundos para a compra e preservação da última casa de Austen, Chawton Cottage, e a fundação da primeira Jane Austen Society (JAS), em 1940. O objetivo de adquirir Chawton para transformá-la em um museu só foi atingido em 1947 pela caridade de um rico advogado chamado T. Edward Carpenter. Ele comprou a casa e a doou para a sociedade porque seu filho, Philip John Carpenter, que havia morrido na guerra, era um grande admirador de Austen. O museu hoje conta com uma placa em homenagem ao tenente Carpenter, e, como nota Claudia Johnson (2012, p. 141), "Chawton Cottage became his memorial as much as it is a museum devoted to Austen herself (...) The monument and museum together suggest that Austen is what Philip John Carpenter fought and fell for". A 
história de Chawton Cotttage se torna, assim, a representação perfeita de como Austen veio a se tornar patrimônio nacional inglês. Mas, como demonstra Deidre Lynch, a escolha da autora para representar a essência da Inglaterra significou a exclusão de muitas outras imagens:

The creation of the Austen Society, the proliferation of Shakespeare festivals, and the curricular rise of "English" were so many early-twentieth-century testimonies to the notion that select literary works constituted a preserve for real Englishness. Such Englishness metamorphosed in turn between 1918 and 1945. The idiom of that identity politics moved away from outsized epic rhetoric suited to imperial missions toward an emphasis on the 'inward-looking, domestic, and private' and toward the proposition that the real locus of national history was the middle-class woman's life in a house. [...] This story nominated rural England - more specifically the landscape of the 'Home Counties' (to the exclusion of the Midlands and North England) - as the site of that all but lost traditional national essence. (LYNCH, 1996, p. 159-169).

Não só uma escolha geográfica, mas também uma escolha de classe. Para Clara Tuite (2002), a redescoberta atual de Austen representa e divulga uma versão específica da GrãBretanha de uma forma geral, a saber, a de sua elite rural, construindo uma ficção de que aquele período histórico não era baseado em uma incrível desigualdade. As pessoas hoje não hesitam em tomar as grandes mansões que veem em filmes como patrimônio histórico representativo de toda a população e não apenas de um exclusivo grupo de aristocratas (TUITE, 2002, p.13). Curiosamente, são estes mesmos filmes e adaptações para a televisão que parecem garantir a contínua popularidade de Austen, ao mesmo tempo em que transcendem a leitura dos romances. Como afirma Deidre Lynch (2005, p. 117), vemos fãs passearem em mansões usadas como cenários que Jane Austen nunca viu e inspecionar roupas feitas para os filmes que as pessoas do século XIX nunca usaram. Rachel Brownstein é 
ainda mais categórica ao afirmar que a chamada Austenmania das últimas décadas combinou uma obsessão com a autora com uma dispensa, ou uma leitura superficial e arrogante e uma reescritura condescendente, do que ela escreveu (BROWNSTEIN, 2011, p.4). Diz ainda que:

Contrary to the main current popular opinion today, Jane Austen's novels are not first of all and most importantly about pretty girls in long dresses waiting for love and marriage; and they are not most importantly English and Heritage, small and decorous and mannerly and pleasant. Read with any degree of attention, they do not work well as escape reading. [...] Obsessed with sentimental nostalgia and the self-congratulatory pleasures of repetition, real profits, and ideal lovers and breasts, twenty-first-century Jane-o-mania has come a long way from the novels, and for the most part has even lost them. [...] Jane-o-mania, in its wrongheadedness and banality, reveals our own inadequacies: stupidity and ignorance, arrogance and greed, the qualities Jane Austen mocked. (BROWNSTEIN, 2011, p. 247).

Paradoxalmente, portanto, a Austenmania atual consiste de fato em um fenômeno literário, porém é baseado na combinação de uma leitura superficial dos romances com uma superexposição da autora em outras mídias. Afinal de contas, como lembrou a escritora inglesa Hilary Mantel (2007, p. 82), "no one who read it closely was ever comforted by an Austen novel". Não é de se estranhar, portanto, que a homenagem do governo britânico na nota de dez libras traga elementos muito mais conectados com essa imagem atual de Austen do que com a vida da autora ou com uma leitura cuidadosa das questões de poder e gênero dentro da sociedade do início do século XIX. A sociedade que a identidade nacional inglesa deseja como base é a do chá da tarde na casa de campo e Austen foi escolhida para ser a sua fotógrafa. Contudo, como seus romances habilmente desnudam as fraquezas desse retrato idílico, era necessário um processo de ressignificação. Austen, portanto, do último quartel 
do século XIX até hoje, vem sendo purificada de suas críticas e transformada na coluna que sustenta a essência inglesa, consumida nacionalmente via adaptações e turismo literário e exportada, nessas amarras, para os outros países.

\section{REFERÊNCIAS}

BROWNSTEIN, Rachel. Why Jane Austen? New York: Columbia University Press, 2011.

HARMAN, Claire. Jane's Fame: How Jane Austen Conquered the World. New York: Henry Holt, 2009.

JOHNSON, Claudia .Jane Austen's Cults and Cultures Chicago: University of Chicago Press, 2012.

KIPLING, Rudyard. "The Janeites" [1926]. Disponível em: http://www.telelib.com/authors/K/KiplingRudyard/prose/DebtsandCredits/janeites.html Acesso em: 15 maio 2018.

LYNCH, Deidre. "At Home with Jane Austen". In: LYNCH, D.; WARNER, W. (Ed.) Cultural Institutions of the Novel. Durham: Duke University Press, 1996, p.159-192.

Cambridge: Cambridge University Press, 2005, p. 111-120.

MANTEL, Hilary. “Jane Austen”. In: EPSTEIN, J. Literary Genius: 25 Classic Writers Who Define English \& American Literature. Philadelphia: Paul Dry Books, 2007, p. 75-82.

PRIDE and Prejudice. Direção: Robert Z. 118m. Leonard Studio: MGM, 1940.

SUTHERLAND, Kathryn. Jane Austen's Textual Lives: From Aeschylus to Bollywood. Oxford: Oxford University Press, 2005.

TUITE, Clara. Romantic Austen: Sexual Politics and the Literary Canon. New York: Cambridge University Press, 2002.

WOOLF, Virginia. "Virginia Woolf on Jane Austen. A review of the publication of R.W. Chapman's edition of the Novels of Jane Austen, in Five Volumes" [1924]. Disponível em: https://newrepublic.com/article/115922/virginia-woolf-jane-austen. Acesso em: 20 maio 2018.

Artigo recebido em: 28 de maio de 2018 Artigo aprovado em: 23 de agosto de 2018 